Journal of Education and Vocational Research

Vol. 3, No. 9, pp. 297-302, Sep 2012 (ISSN 2221-2590)

\title{
Presents Spoken Texts in Multimedia Instructions as an Alternative to Printed Texts
}

\author{
Khayrazad Kari Jabbour \\ Lebanese University, Hammana, Lebanon \\ karijabbour@hotmail.com
}

\begin{abstract}
Multimedia instructions refer to presentations that contain graphics and texts information. The graphics can include pictures, drawings, diagram, chart, animation, video, or simulations. In addition, texts can include printed texts or spoken texts. Multimedia education occurs when learners create mental representations caused by combining texts and relevant graphics simultaneously in lessons. Research evidence shows that not all multimedia instructions are equally useful. How can we use multimedia instructional to help learners to grasp knowledge? Do learners learn better when multimedia instructions present spoken text in multimedia instructions as an alternative to printed text principle? This article examines whether there is any benefit on supplementing spoken text with multimedia. Specifically, do learners learn more from spoken text and graphics, rather than from printed text and graphics? Meaningful learning engages the learner into excessive cognitive load processing during learning; on the other hand, the learner's cognitive capacity is limited. For that, reasons multimedia instructional designers must take into account the learner's cognitive load processing. One of the obstacles of multimedia instructions is the possibility of overloading the learners' cognitive capacity. Multimedia instructional designers must design multimedia instruction in ways that minimize the possibility of overloading the learners' cognitive capacity. Also will examines the limitations of presenting spoken rather than printed texts; Reasons for presenting spoken rather than printed texts; Evidence for Using Spoken Rather Than Printed Text; And when this principle applies.
\end{abstract}

Keywords: Multimedia instructions, Active Learning, Cognitive theory, Instruction, Graphics, Printed Text, Spoken Text

\section{Introduction}

Multimedia instructions typically consists of printed or spoken texts as the primary way for conveying information in conjunction with graphics, which include static graphics such as drawings or photos or dynamic graphics like animation or video. There are strong and reliable evidence that learners obtain more knowledge from texts and graphics than from words alone. Many researches confirm this evidence; Richard Mayer in 1989, argued that multimedia supports the way the human brain learns efficiently. Clark \& Mayer articulated, "Multimedia presentations can encourage learners to engage in active learning by mentally representing the material in words and in pictures and by mentally making connections between the pictorial and verbal representations. In contrast, presenting words alone may encourage learners especially those with less experience or expertise-to engage in shallow learning such as not connecting the words with other knowledge"( Clark \& Mayer, 2011). In this article examines whether when the multimedia instructions consist of texts of information in combination with graphics, do learners learn better when the texts in the multimedia instruction are represented as printed text or as spoken text? Meaningful learning is an effective process of grasping new knowledge, and combines it with related existing knowledge. Mayer \& Wittrock define Meaningful learning as the capability to recall the knowledge that was taught into another relevant circumstance (Mayer \& Wittrock, 1996). Research shows that meaningful learning engages the learner into excessive cognitive load processing during learning; on the other hand, the learner's cognitive capacity is limited. For that reasons multimedia instructional designers must take into account the learner's cognitive load processing (Clark, 1999; Kalyuga, Chandler, \& Sweller, Sweller, 1999; van Merriënboer, 1997). One of the obstacles of multimedia instructions is the possibility of overloading the learners' cognitive capacity. Multimedia instructional designers must design multimedia instruction in ways that minimize the possibility of overloading the learners' cognitive capacity. In this article, we describe evidence of multimedia 
instructional benefits of using Spoken texts rather than printed texts to describe instructions. Especially when the multimedia instructions are ambiguous or complicated and when the Spoken information is friendly or brief. The spoken texts must be concise and unambiguous to be helpful. This article also examines several circumstances where the limitations of the scholars working memory necessitate the use of printed text rather than Spoken text.

\section{Present Spoken text Rather than Printed text}

Many research evidence, including the cognitive theory, have recommend to use spoken text in multimedia instructions as an alternative to printed text whenever the graphic is the focus of the texts and are presented at the same time. Especially when the multimedia instructions are complicated or ambiguous and when the Spoken information is friendly, and the lesson are fast-paced or brief. Particularly, the spoken texts must be concise and unambiguous to be helpful. It has been suggested to stay away from multimedia learning instructions that contain important multimedia instructions where all texts are in printed rather than spoken type. The underlying principle of this recommendation is that learners may suffer overstrain of their visual channel when the brain try to process graphics and the printed texts that refer to them information at the same time. If the Lerner vision has to apply their mind to the printed text part of the multimedia instruction, they cannot utterly apply their mind to the graphics part. In particular, when the texts and graphics are presented at the same time and at a fast speed, the texts are easy and friendly, and the graphic is complicated or ambiguous. In view of the fact that learners must be able to focus on correlated texts and graphics, it is important for the instructions to be designed in a way reduce the possibility of overcrowding the learners' visual channel. The following example, in the figure 1, illustrates a multimedia instruction that providing a demonstration of how to use a Pilot Model system. As the graphics illustrates the steps on the computer screen, the Spoken texts describes the actions of the navigation. In this example, the visuals graphic is relatively complicated and ambiguous, and therefore using Spoken texts allows the learner to focus on the visual instruction while listening to the clarification.

Figure 1: multimedia instruction of how to use a Pilot Model system

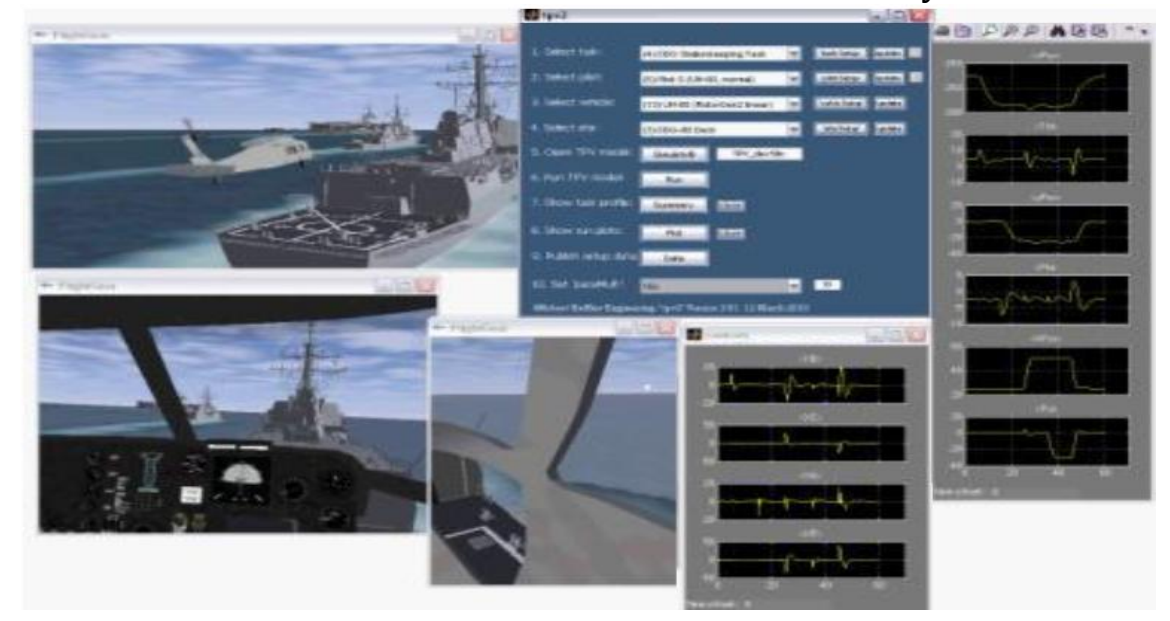

Limitations: When multimedia instructions, in concurrently, presents graphics and spoken text rather than printed text in order to lower the stress on the learner visual processing. However, there are some circumstances it may not be functional to apply graphics and spoken texts. For instances, the design of spoken texts in multimedia instructions may demand learning environment that cannot be meet, such as not having the necessary bandwidth; when the computer doesn't have a sound card or headsets; When the spoken texts instructions generate a great deal noise in the learning background. Utilizing spoken texts in multimedia instructions may also add unnecessary cost; and in some circumstances, it may become problematical to update frequently changing information. Those restrictions are limited to circumstances in which the texts and graphics are presented at the same time. In addition, do not valid when the texts are presented without any concurrent graphics. In addition, there are some circumstances when the texts must 
be available to the learner over an extensive duration of time in order to support memory; especially when the texts are usual technical expressions, unfamiliar language, out of the ordinary phrase, or require additional references. For instance, in solving arithmetic equations, the math formula may be part of spoken texts explanation of multimedia instruction, but for the reason of its complexity, it should continue to be visible to the learners as printed text for a period in order to support memory. Technical terms or phrases that used to identify complicated science, high technical issues, or new technology. Another examples involves medical science illustrations or medication and drug when the information may be presented by printed text and are illustrated in the animation and discussed in the Spoken texts, see Figure 2.

Figure 2: Medical science illustrations

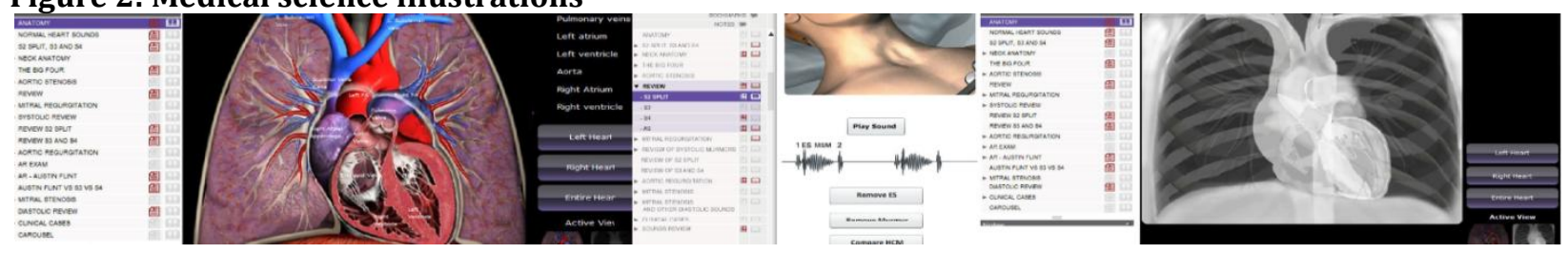

As a rule, multimedia instructional designers should careful place spoken texts in instructions that require memory support, practice directions, and technical terms.

\section{How Learners Process Information}

In order to illustrate the cognitive overload and how to minimize it, we have to understand the human memory and how learners process information. The learners memory receives the instructions, processes it and saves it be used for later on. The human has three memories: the Sensory Memory, Working Memory, and Long-term Memory. The sensory memories receive the information through the five senses of sight, hearing, smell, taste and touch using. The working memory is the thinking or the processing center of the consciousness. It processes the information that collected through the five senses. Working memory is generally considered to have limited capacity; it can store around 7 pieces of information at a time. The information in the working memory only lasts about 12 seconds without elaborate rehearsal. As a final point the long-term memory, permanently store the processed information-knowledge, to be utilized later. The long-term memory has a huge capacity for storing information. The schema is a specialized memory structures that organize the information into categories, it also link up the new information to previous knowledge. The human mind is continually in receipting of new knowledge. It also makes an effort to relate the new information to prior stored knowledge. When the human require the knowledge, the schemas get the information from the long-term memory, and pass it to the working memory. The possibility of overloading the learners' cognitive capacity, take place mainly in the working memory. As we explained previously the working memory has limited storage capacity; when a great deal information is moved from the sensory memories into the short-term memory (working memory), the working memory will no longer be able to process all the material that is being offered. This will create overload of the learners' cognitive capacity. When the human sense new information, our sensory memories receive all type of information. The working memory processes that information. After processing the information into knowledge that we can memorize it, we store the information in the long-term memory. If a learner needs to further process the knowledge, he/she bring back that information from the long-term memory into the working memory. Figure 3 , shows how human memory process information.

Figure 3: How human memory process information

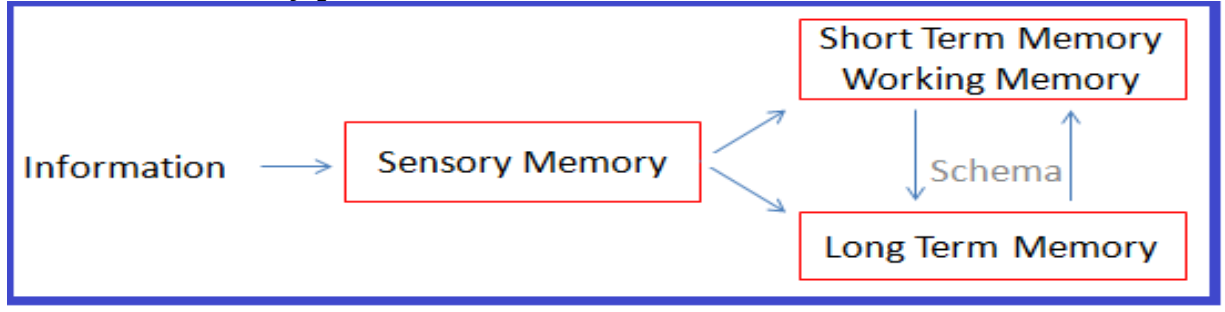


Reasons for Presenting Spoken Rather Than Printed Texts: The objective of Multimedia Instructions is to utilize texts and graphics to promote knowledge. The texts can be printed texts or spoken texts. The questions that come to mind: Does it make any difference whether the instructions includes graphics with printed text or graphics with spoken text. In both cases, the same graphics and texts are offered, so it does it make any difference whether the texts are printed texts or spoken texts. Research evidence with respect to the basic principles for how people learn, showed that, the purpose of the instructional program is not only to present information, but also to present the material in a way that is consistent with principles of how people learn. Printed texts are far easier, cost less to produce and manage than spoken text. However, multimedia instructions that introduce texts as printed text can create a condition that inconsistent with the way the human mind functions. According to the cognitive theory of learning, instruction should depend on the material that is presented and on the cognitive processes that is used by the learner during gaining of knowledge (Chandler \& Sweller, 1991). Mayer (2005) argues that Cognitive Theory of Multimedia Learning assumes that humans have separate information processing channels: one for visual processing and another for spoken processing (Mayer, 2005). This theory was originally introduced by Paivio in 1986 \& 1990, as the Dual coding theory. The Dual-coding theory assumes that humans have two different systems for mental representation; one system focus on the spoken information and the other focus on nonverbal information (Paivio, 1990). Of particular interest, the use of multimedia instructions enhances the ability to establish a mental representation and connections between the verbal and nonverbal information (Mayer 2005). When multimedia instructions present simultaneous graphics and printed text, initially, both have to be processed in the visual channel. Each channel has a limited capacity; as a result, the printed text and graphics have to be proceeding at the same visual channel simultaneously. This might cause the visual channels to become overloaded. Consequently, in spite of the fact that the information is presented, human mind may not be able to effectively focus on all the information at the same time, for the reason that their visual channels become overloaded. Alternatively, we can minimize visual channel overload by presenting Spoken texts instead of printed texts. As a result, the Spoken material goes through the ears and is processed in the auditory channel. Simultaneously, the graphics enter through the eyes and are processed in the visual channel. As a result, neither channel will be overloaded although both texts and graphics are processed simultaneously. Figures 4a shows how graphics and printed texts can overwhelm the visual channel. Figure $4 \mathrm{~b}$ shows how graphics and Spoken texts can split up the processing between the visual and auditory channels.

Figure 4a: graphics and printed text

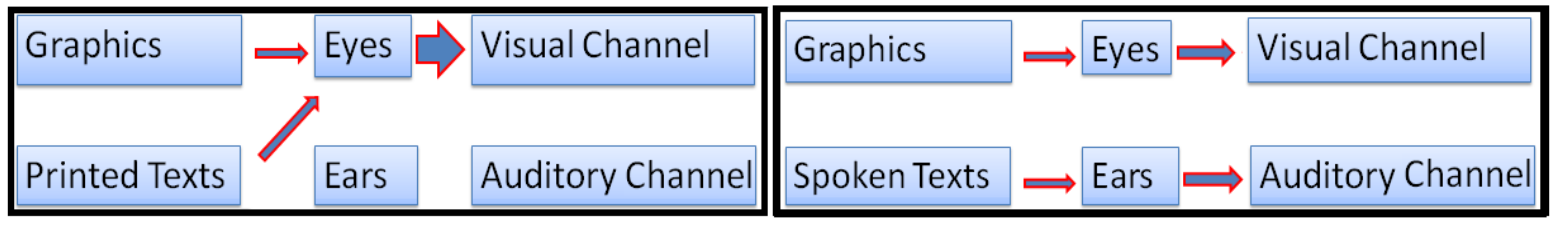

\section{Evidence for Using Spoken Rather Than Printed Text}

Many research studies have shown that students learn at a highest degree from graphics in combination with spoken text than from graphics in combination with printed text, as suggested by cognitive theory. In which the words in the spoken text and printed text are identical, and they were presented at identical instant with the graphics. For example, a study done by Moreno \& Mayer in 1999, in which they had two groups of students examining illustration steps of lightning formation process. The first group of students examines graphics along with concurrent spoken text. The second group of students examines graphics along with concurrent printed text. In his experiment studies, Moreno \& Mayer discover that the first group, the animation-with-Spoken text group, performed better on the assessment than the second group-the animation-with-printed text group. The Dr. Phyz's study is another study that showed similar result. In an interactive setting where students could learn about how electric motors works. Students could ask questions and receiving short animated answer along with spoken text or printed text. The students were divided into two groups. In the first group, students examine graphics along with concurrent spoken text. The second group of students examines graphics along with concurrent printed text. On a subsequent test in which students had to solve problems about electric motors, the animation-with spoken text group achieved better 
as compared to the animation-with-text group. As a result, students learn more deeply from multimedia lessons when texts illustrate simultaneous graphics are presented as spoken text more than as printed text (Mayer, Dow, \& Mayer, 2003). Another research study by in 2007 has shown similar results. Harskamp, Mayer, \& Suhre in 2007 observed that high school students learned better from web-based biology instructions that contained graphic in combination with spoken text more than instructions containing graphic in combination with printed text (Harskamp, Mayer, \& Suhre, 2007). Other studies have shown similar results: Study shown the development of lightning (Craig, Gholson, \& Driscollin, 2002); Vehicle break system (Mayer, Dow, \& Mayer, 2003); Electric motor (Mayer \& Moreno, 1998 \& Moreno \& Mayer, 1999); Botany (Moreno, Mayer, Spires, \& Lester, 2001; Moreno \& Mayer, 2002); Aircraft fuel system (O'Neil, Mayer, Herl, Niemi, Olin, \& Thurman, 2000). A recent eye tracking research study conducted in 2010, that is consistent with spoken text in multimedia instructions as an alternative to printed text, revealed that learners who perceive graphics with spoken text spent more time observing the graphics than did learners who received graphics with printed text (Schmidt-Weigand, Kohnert, \& Glowalla, 2010a, 2010b). Also in consistent with spoken text in multimedia instructions as an alternative to printed text, researchers have uncover that most effective benefits were for less knowledgeable learners than for knowledgeable learners (Seufert, Schutze, \& Brunken, 2009). Ginns (2005) found that the effective benefits was stronger for more complicated information than for less complicated information, and more effective for PC controlled than for learners controlled.

\section{Conclusion and Discussion}

Multimedia instructional design combines words and graphics to enhance learning effectiveness. Using Multimedia instructions can help learners engage in active learning. However, not all multimedia instructions are equally effective. This article demonstrates the learning advantage of presenting spoken text in multimedia instructions as an alternative to printed text. The advantages of integrating spoken text as an alternative to printed text domino effect from minimize the cognitive load in the learner's visual channel (through the eyes) by relieving some of the load processing into the spoken channel (through the ears). Thus, allow the learners to dedicate his/her cognitive memory to understanding the materials. Again, we need to maintain balance, not to overuse spoken text. Many researchers have recommended being flexible and not rigid in applying this principle to all situations. Decisions should be made in ways that are in harmony with respect to how human mind functions. That is in harmony with the cognitive theory of multimedia learning. Choosing the best multimedia instructional for learning objectives depends on the instructional goals, stages of learning, and the learners' knowledge level who will participate. Applying spoken text in multimedia instructions as an alternative to printed text principle applies in circumstances in which graphics and Spoken texts presented at identical point in time and space. In addition, mainly, when the information is complicated and offered at a fast constant rate. If the information presented are simple and straightforward, or the learner has the power over managing the rate of the information, the spoken text as an alternative to printed text principle becomes less important. As we mentioned earlier, some circumstances requires that printed texts should remain available to the learner over period. Mainly if the texts are peculiar, high technical terms, unfamiliar, foreign language, or lengthy. Additionally, if the instruction present only printed texts not including any corresponding graphic, then applying spoken text as an alternative to printed text principle is not valid. In conclusion, in some circumstances students may possibly learn better from multimedia instructions that presents few well placed printed texts simultaneous with spoken texts.

\section{References}

Chandler, P. \& Sweller, J. (1991). Cognitive load theory and the format of instruction. Cognition and Instruction, 8, 293-332.

Clark, R. C. (1999). Developing technical training (2nd Ed.). Washington, DC: International Society for Performance Improvement.

Clark, R. \& Mayer, R. (2011). E Learning and the Science of Instruction (3rd Ed.) San Francisco: Pfeiffer.

Craig, S. D., Gholson, B. \& Driscoll, D. M. (2002). Animated pedagogical agents in multimedia learning environments: Effects of agent properties, picture features, and redundancy. Journal of Educational Psychology, 94, 428-434. 
Ginns, P. (2005). Meta-analysis of the modality effect. Learning and Instruction, 15, 313-331.

Harskamp, E. G., Mayer, R. E. \& Suhre, C. (2007). Does the modality principle for multimedia learning apply to science classrooms? Learning and Instruction, 17, 465-477.

Holsanova, J., Holmberg, N. \& Holmqvist, K. (2009). Reading information graphics: The role of spatial contiguity and dual attention guidance. Applied Cognitive Psychology, 23, 1215-1226.

Kalyuga, S., Chandler, P. \& Sweller, J. (1999). Managing split attention and redundancy in multimedia instruction. Applied Cognitive Psychology, 13, 351-372.

Mayer, R. E. (2005). Principles for managing essential processing in multimedia learning: Segmenting, pretraining, and modality principles. In R.E. Mayer (Ed.), The Cambridge handbook of multimedia learning (147-158). New York: Cambridge University Press.

Mayer, R. E. \& Moreno, R. (1998). A split-attention effect in multimedia learning: Evidence for dual processing systems in working memory. Journal of Educational Psychology, 90, 312-320.

Mayer, R. E. \& Wittrock, M. C. (1996). Problem-solving transfer. In D. Berliner \& R. Calfee (Eds.), Handbook of educational psychology (45-61). New York: Macmillan.

Moreno, R. \& Mayer, R. E. (1999). Cognitive principles of multimedia learning: The role of modality and contiguity. Journal of Educational Psychology, 91, 358-368.

Moreno, R. \& Mayer, R. E. (2002a). Verbal redundancy in multimedia learning: When reading helps listening. Journal of Educational Psychology, 94, 156-163.

Moreno, R., Mayer, R. E., Spires, H. \& Lester, J. (2001). The case for social agency in computer-based teaching: Do students learn more deeply when they interact with animated pedagogical agents? Cognition and Instruction, 19, 177-214.

O’Neil, H. F., Mayer, R. E., Herl, H. E., Niemi, C., Olin, K. \& Thurman, R. A. (2000). Instructional strategies for virtual aviation training environments. In H.F. O'Neil \& D.H. Andrews (Eds.), Aircrew training and assessment (105-130). Mahwah, NJ: Lawrence Erlbaum Associates.

Paivio, A. (1990). Mental representations: A dual-coding approach. New York: Oxford University Press.

Schmidt-Weigand, F., Kohnert, A. \& Glowalla, U. (2010a). A closer look at split attention in system- and selfpaced instruction in multimedia learning. Learning and Instruction, 20, 100-110.

Schmidt-Weigand, F., Kohnert, A. \& Glowalla, U. (2010b). Explaining the modality and contiguity effects: New insights from investigating students' viewing behavior. Applied Cognitive Psychology, 24, 226-237.

Seufert, T., Schutze, M. \& Brunken, R. (2009). Memory characteristics and modality in multimedia learning: An aptitude-treatment interaction study. Learning and Instruction, 19, 28-42.

Van-Merriënboer, J. J. G. (1997). Training complex cognitive skills. Englewood Cliffs, NJ: Educational Technology Press. 